\title{
Caring competencies of baccalaureate nursing students of samar state university
}

\author{
Leodoro J. Labrague \\ College of Nursing, Samar State University, Catbalogan City, Philippines \\ Correspondence: Leodoro J. Labrague. Address: College of Nursing, Samar State University, Catbalogan City, \\ Philippines. Email: Leo7_ci@yahoo.com \\ Received: January 15, 2012 \\ Accepted: April 8, 2012 \\ Published: November 1, 2012 \\ DOI : 10.5430/jnep.v2n4p105 \\ URL: http://dx.doi.org/10.5430/jnep.v2n4p105
}

\section{Abstract}

Background: Caring is a core nursing value and a desirable attribute in nursing students. This study was conducted to investigate and determine student nurses' caring competencies as perceived by patients. Furthermore, it proposed a caring intervention guide which could be used to build and enhance student's caring behaviors that can be adapted to clinical situations.

Methods: This investigation primarily employed a descriptive research design to determine the caring competencies of Level IV students of Samar State University as perceived by the patients. A non-probability purposive sampling was utilized in this study. A total of 174 patients who were admitted in the different units of the hospital were taken as respondents. To examine the caring competencies of nursing students, the investigator utilized the modified Cronin and Harrison's Caring Behavior Assessment Tool. This tool is a 63-item questionnaire that uses a 5-point Likert scale and is based on Watson's ten Carative Factors and is designed to capture patients' perceptions of nurses' caring behaviors.

Results: Results showed that "Know how to give shots, IVs, etc", "Kind and considerate", "Help me feel good about myself", and "Give me treatments and medications on time", were the highest ranked caring behaviors of student nurses. The subscale "human needs assistance" was rated as highest by patient respondents. The results generated the caring intervention guide that would assist nurse educators to improve students' caring practices.

Conclusion: Findings give high regards to Jean Watson's assumptions that caring is demonstrated by using actions based on theoretical knowledge that help patient to achieve health while maintaining respect, self-worth and autonomy.

\section{Key words}

Caring, Caring intervention, Caring competency, Caring behavior assessment

\section{I ntroduction}

Caring is a core nursing value ${ }^{[1]}$ and has been considered as a major component, an important indicator, and a foundation of quality nursing education. It is an expectation of patients and their families and is the predominant adjective used by nursing students and nurses to characterize nursing practice ${ }^{[2]}$.

Researchers have demonstrated that patients who feel they have been cared for report a higher level of satisfaction ${ }^{[3,4]}$ and possess effective coping skills ${ }^{[5]}$. Schultz et al. suggest that patients equate their perception of caring to the level of 
competency of the care giver ${ }^{[6]}$. On the contrary, the perception of an uncaring environment can lead to increased anxiety and diminished coping abilities ${ }^{[7]}$.

Nursing education has a vital role in educating nurses with adequate caring abilities. Woodward postulated that human caring, while instinctive, can also be taught, learned, and measured through nursing education system. He believes that nursing students can be professionally trained to develop the competency of caring through the concepts of modeling and role modeling ${ }^{[8]}$. Meanwhile, Carlson, Kotze, and Rooyen have noted that "the clinical learning environment creates many opportunities for student learning and the development of critical competencies in the nursing profession. Such competencies include the core competency of caring ${ }^{[19]}$. Therefore, it is paramount that nursing students' performance on this indicator at the time of graduation be validated for it provides evidence on the success of the nursing education program.

Although the body of evidence regarding nursing caring attitude towards its patient is growing over the world, there is little in the literature assessing students and nursing graduates' caring competencies. It is in the context that the investigator was motivated to conduct this investigation. The knowledge that could be gained in this investigation would provide direction for educational and curricular development for nursing educators.

\section{Research problem}

This study was conducted to investigate and determine student nurses' caring competencies as perceived by patients. Furthermore, it proposed a caring intervention guide which could be used to build and enhance caring behaviors that can be adapted to clinical situations.

\section{Methodology}

\subsection{Design}

The investigator utilized the descriptive method of research to determine the caring competencies of Level IV nursing students of Samar State University. The study was conducted in the different clinical units of Samar Provincial Hospital, Catbalogan City, Philippines.

\subsection{Participants}

A non-probability purposive sampling was utilized in this study, wherein 174 patients participated in the investigation. The patient-respondents were taken without regard to their diagnosis. However, inclusion criteria were set for the purpose of delimitation. Respondents were taken from patients in the different wards of Samar Provincial Hospital. Furthermore, inclusion criterions were set for study participation among patient as follows: (1) parents of children and patients with age eighteen years and older, (2) patients who can read, (3) patients who agree and signed consent to participate in the study, (4) patients with assigned student nurse, and (5) are presently admitted in the different units of the hospital. The questionnaires were given to the patient or parent during their admission and stay in the units and were completed and recollected before discharge from the units. The investigator utilized a questionnaire in gathering the necessary data to answer the research questions.

\subsection{Ethical consideration}

The investigator sought the approval of the Ethics Committee of Samar Provincial Hospital prior to the conduct of the investigation. Precautionary measures were taken into consideration to safeguard the study respondents' legal rights. Prior to the interview, consent forms were given to the respondents and have them read and signed it. Confidentiality and anonymity of the respondents were maintained by only a code number on the questionnaire. 


\subsection{I nstrument}

To examine the caring competencies of nursing students, the investigator utilized the modified Cronin and Harrison's Caring Behavior Assessment (CBA) Tool after seeking the permission of its authors ${ }^{[17]}$. This tool is a 63-item questionnaire that uses a 5-point Likert scale and is based on Watson's ten Carative Factors. This tool is designed to capture patients' perceptions of nurses' caring behaviors. The tool used 63 nursing behaviors that patients rated on a fixed five-point Likert scale in terms of level of importance, but in this study the investigator revised the Likert scale in terms of degree of caring. Scores assigned to each item are between 1 and 5 points as follows; (Always, Often, Sometimes, Rarely, and Never).

\subsection{Data analysis}

Descriptive approached was utilized to analyze the data. Descriptive statistics included frequency, percentage, mean, standard deviation to describe the demographic characteristics and CBA items. Data were analyzed using SPSS version 11.0 .

\section{Results}

The patient-respondents age ranges from 19 to 92 years with a mean of 39.62 years and standard deviation of 16.35 years. Majority of them were female $(n=125)$ and married $(n=124)$. Most of the respondents were college undergraduate $(n=57)$. Their demographic characteristics are given in Table 1.

Table 1. Demographic Characteristics of the Patient- Respondents

\begin{tabular}{llll}
\hline Characteristics & & $\mathbf{n}$ & $\mathbf{\%}$ \\
\hline Age & & 174 & 100 \\
Sex & Female & 125 & 71.84 \\
& Male & 49 & 28.16 \\
Marital Status & Single & 12 & 6.90 \\
& Married & 124 & 71.26 \\
& Live-in & 22 & 12.64 \\
Education & Widowed & 16 & 9.20 \\
& College Graduate & 39 & 22.41 \\
& College Undergraduate & 57 & 32.76 \\
& High School Graduate & 34 & 19.54 \\
& High School Undergraduate & 20 & 11.49 \\
& Elem. Graduate & 19 & 10.92 \\
\hline
\end{tabular}

Table 2 discusses the information obtained from respondents regarding the caring competencies of student nurses on the seven subscales. Mean scores were computed for each of the Caring Behavior Assessment (CBA) items consisting of 7 subscales which ranged from 3.17 to 4.84 (See table 2).

Of 63 caring behaviors, "Know how to give shots, IVs, etc", "Kind and considerate", "Help me feel good about myself", "Give me treatments and medications on time", "Seem to know how I feel", and "Know what they're doing” were the highest ranked caring behaviors of student nurses. Meanwhile, "Talk to me about my life outside the hospital”, “Ask me what I like to be called”, “Tell me what to expect during the day”, "Introduce themselves to me”, and "Don’t become upset when I'm angry” were the lowest ranked caring behaviors in the CBA.

Majority of the items rated as "Very Satisfactory Caring Behavior" by student nurses were part of the Humanism/Faith/Hope/Sensitivity subscale that was ranked second overall in the lists of behaviors manifested by student 
nurses. While all items rated as "Moderately Satisfactory Caring Behavior” were part of Helping/Trust subscale that was ranked sixth in overall degree of caring.

In general, student nurses possess “Satisfactory Caring Behavior” with a grand mean of 4.38.

Table 2. Ratings of the Caring Behavior Assessment Items

\section{Caring Behavior Assessment}

Humanism/Faith-Hope/Sensitivity

Treat me as individual.

Try to see things from my point of view.

Know what they're doing.

Reassure me.

Make me feel someone is there if I need them.

Encourage me to believe in myself.

Point out positive things about me and my condition.

Praise my efforts.

Understand me.

Ask me how I like things done.

Accept me the way I am.

Sensitive to my feelings and moods.

Kind and considerate.

Know when I've "had enough” and act accordingly (for example, limiting visitors).

Maintain a calm manner.

Treat me with respect.

\section{Helping/Trust}

Really listen to me when I talk.

Accept my feelings without judging them.

Come into my room just to check on me.

Talk to me about my life outside the hospital.

Ask me what I like to be called.

Introduce them selves to me.

Answer quickly when I call for them.

Give me their full attention when with me.

Visit me when I move to another hospital unit.

Touch me when I need it for comfort.

Do what they say they will do.

\section{Expression of positive/negative feelings}

Encourage me to talk about how I feel.

Don't become upset when I'm angry.

Help me understand my feelings.

Don't give up on me when I'm difficult to get along with.

\section{Teaching/Learning}

Encourage me to ask questions about my illness and treatment.
Mean Scores

4.71

4.66

4.73

4.44

4.43

4.34

4.45

4.46

4.70

4.34

4.68

4.27

4.80

4.29

4.65

4.71

Mean Scores

4.56

4.54

4.56

3.18

3.19

3.60

4.63

4.37

3.87

4.29

4.56

Mean Scores

4.37

3.75

4.34

3.76

Mean Scores

4.44
Interpretation

VSCB

VSCB

VSCB

SCB

SCB

SCB

SCB

SCB

VSCB

SCB

VSCB

SCB

VSCB

SCB

VSCB

VSCB

Interpretation

VSCB

VSCB

VSCB

MSCB

MSCB

SCB

VSCB

SCB

SCB

SCB

VSCB

Interpretation

SCB

SCB

SCB

SCB

Interpretation

SCB 
Table 2. (Continued.)

\begin{tabular}{|c|c|c|}
\hline Answer my questions clearly. & 4.62 & VSCB \\
\hline Teach me about my illness. & 4.43 & SCB \\
\hline Ask me questions to be sure I understand. & 4.61 & VSCB \\
\hline Ask me what I want to know about my illness/health. & 4.45 & SCB \\
\hline Help me set realistic goals for my health. & 4.31 & SCB \\
\hline Help me plan ways to meet those goals. & 4.29 & SCB \\
\hline Help me plan for my discharge from the hospital. & 4.11 & SCB \\
\hline Supportive/Protective/Corrective Environment & Mean Scores & Interpretation \\
\hline Tell me what to expect during the day. & 3.55 & SCB \\
\hline Understand when I need to be alone. & 4.27 & SCB \\
\hline $\begin{array}{l}\text { Offer things (position changes, blankets, back rub, lighting, etc.) to make more } \\
\text { comfortable. }\end{array}$ & 4.55 & VSCB \\
\hline Leave my room neat after working with me. & 4.22 & SCB \\
\hline Explain safety precautions to me and my family. & 4.36 & SCB \\
\hline Give me pain medication when I need it. & 4.34 & SCB \\
\hline Encourage me to do what I can for myself. & 4.30 & SCB \\
\hline Respect my modesty (for example, keeping me covered). & 4.31 & SCB \\
\hline $\begin{array}{l}\text { Check with me before leaving the room to be sure I have everything I need } \\
\text { within reach. }\end{array}$ & 4.21 & SCB \\
\hline Consider my spiritual needs. & 4.38 & SCB \\
\hline Are gentle with me. & 4.61 & VSCB \\
\hline Are cheerful. & 4.56 & VSCB \\
\hline Human needs assistance & Mean Scores & Interpretation \\
\hline Help me with my care until I'm able to do it for myself. & 4.54 & VSCB \\
\hline Know how to give shots, IVs, etc & 4.84 & VSCB \\
\hline Know how to handle equipment (for example, monitors). & 4.59 & VSCB \\
\hline Give me treatments and medications on time. & 4.78 & VSCB \\
\hline Keep my family informed of my progress. & 4.37 & SCB \\
\hline Let my family visit as much as possible. & 4.55 & VSCB \\
\hline Check my condition very closely. & 4.71 & VSCB \\
\hline Help me feel like I have some control. & 4.53 & VSCB \\
\hline Know when it's necessary to call the doctor. & 4.66 & VSCB \\
\hline Existential/Phenomenological Spiritual forces & Mean Scores & Interpretation \\
\hline Seem to know how I feel. & 4.75 & VSCB \\
\hline Help me see that my past experiences are important. & 3.92 & SCB \\
\hline Help me feel good about myself. & 4.80 & VSCB \\
\hline GRAND MEAN & 4.38 & SCB \\
\hline
\end{tabular}

Legend:

4.51-5.00 Very Satisfactory Caring Behavior $\quad$ (VSCB)

3.51-4.50 Satisfactory Caring Behavior $\quad$ (SCB)

2.51-3.50 Moderately Satisfactory Caring Behavior $\quad$ (MSCB)

1.51-2.50 Fair Caring Behavior $\quad$ (FCB)

1.00-1.50 Poor Caring Behavior 
Table 3 shows the Caring Behaviors Assessment (CBA) subscales for student nurses identified by patients. When items were grouped into the 7 subscales, a mean for all items in each subscale was calculated for each patient. The overall subscale means were then calculated on the basis of the respondents mean scores for each CBA items. Mean Scores of Caring Behaviors Assessment (CBA) Subscales among student nurses indicated that the highest ranked subscale was the Human Needs and Assistance $(m=4.62)$. On the other hand, Expression of positive/negative feelings $(m=4.05)$ was the lowest ranked subscale.

Table 3. Rating of Caring Behaviors Assessment (CBA) Subscales

\begin{tabular}{lll}
\hline Subscales & Mean & Rank \\
\hline Humanism/Faith-Hope/Sensitivity & 4.54 & 2 \\
Helping/Trust & 4.12 & 6 \\
Expression of Positive/Negative Feelings & 4.05 & 7 \\
Teaching/Learning & 4.41 & 4 \\
Supportive/Protective/Corrective Environment & 4.30 & 5 \\
Human Needs Assistance & 4.62 & 1 \\
Existential/Phenomenological/Spiritual Forces & 4.49 & 3 \\
GRAND MEAN & 4.38 & SCB \\
\hline
\end{tabular}

\section{Discussions}

This investigation determined student nurses' caring competencies as perceived by patients. Furthermore, it proposed a caring intervention guide which could be used to build and enhance caring behaviors that can be adapted to clinical situations. It contributes to the growing body of knowledge regarding nursing caring attitude towards their patient.

The findings indicated that the ranked caring behavior was "Know how to give shots, IVs, etc." which was part of the Human Needs Assistance which was also rated as the overall ranked subscale. This subscale is based on the ninth carative factors on Watson's Theory of Caring. These result are congruent to the findings of the study conducted by Misao et al. and Rosenthal, where a similar item was rated high ${ }^{[9,10]}$. This suggests that student nurses possess professional nursing skills necessary to provide safe nursing procedures, vis-à-vis-the best nursing care to their patients. This may be attributed to rigid training they have had during their early years in the program. This result is worth noting since demonstration performances of professional competence as displayed during performances of nursing skills were viewed by respondents as the most important feature of caring based on the previous studies conducted.

On the other hand, "Talk to me about my life outside the hospital" was the lowest ranked item for nurse caring behaviors in the subscale. This subscale is based on the fourth carative factor on Watson' Theory of Caring. This finding is consistent with that of Marini (1995) where in the same item was rated as unimportant ${ }^{[11]}$. This result can be explained into two perspectives. First, it could be an indication of students' unpreparedness in dealing with personal issues and concerns of their patients. Secondly, it could be an indication of students' reluctances in initiating conversation with patients with regards to their personal lives for it may mean invasion to privacy and usually not tolerated in Filipino culture.

Findings of the study also revealed that student nurses possess caring behaviors that give importance to their patients' sense of self by making them feel accepted while maintaining self-worth and while directly addressing patients. These results corroborates with the findings of previous studies ${ }^{[6,7,11-15]}$ conducted where the same subscale pertaining to fulfillment 'of human needs consisting of items that reflect the technical skills of the nurse was also rated as the highest ranked subscale. 
Analysis of the study also suggest that students must work more on encouraging their patients to express their feelings, both positive and negative without being consumed by it. Although patients least likely to acknowledge the importance of those caring behaviors relative to expression of positive and negative feelings as reflected in the study conducted by Baldursdottir and Jonsdottir, it should never be taken for granted since provision of holistic nursing care encompasses not only physiological but emotional aspect of care as well ${ }^{[15]}$.

\section{Caring intervention guide}

This guide was formulated based on the findings of the study and is anchored on the assumptions of Gramling and Mugent which suggest that when caring is introduced early, together with the concept of health, modeled and reinforced throughout the curriculum, students' performance shifted toward mastery making them caring practitioners in the future ${ }^{[16]}$.

This guide focuses on the concept of caring interventions. Caring interventions are those activities that can help students build or enhance their caring behaviors that can be adapted to clinical situations. This would be useful tool for nurse educators who are aiming to improve caring competencies of their students. These interventions are based on a knowledge and understanding of the natural sciences, behavioral sciences, nursing theory, nursing research and past nursing experiences.

Table 4. Caring Intervention Guide

\begin{tabular}{|c|c|}
\hline OBJECTIVES & SPECIFIC ACTIVITIES \\
\hline \multirow{3}{*}{$\begin{array}{l}\text { Formulate activities that would allow nursing students } \\
\text { identify and clarify their own caring behaviors. }\end{array}$} & Self-Awareness Workshop/Activity \\
\hline & Caring Behavior Assessment \\
\hline & Group/Classroom Discussion \\
\hline $\begin{array}{l}\text { Develop strategies to increase the level of knowledge } \\
\text { and understanding of caring practices. }\end{array}$ & Lecture/Seminar on Components of Caring \\
\hline Develop caring-focused teaching strategies. & Infuse caring enrichment activities in every subjects \\
\hline \multirow{3}{*}{$\begin{array}{l}\text { Conceptualize a strategic plan to help nursing students } \\
\text { improve/enhance their caring capabilities. }\end{array}$} & Seminar-Workshop on Role Modeling \\
\hline & Role playing \\
\hline & Group Discussion \\
\hline \multirow{2}{*}{ Strengthen students commitment to the value of caring. } & $\begin{array}{l}\text { Submission of a written journal, Nursing Care Plans (NCP's) and } \\
\text { anecdotal record of demonstration of carative factors. }\end{array}$ \\
\hline & $\begin{array}{l}\text { Summative self-assessment on integration of carative factors during } \\
\text { clinical exposure }\end{array}$ \\
\hline \multirow{2}{*}{$\begin{array}{l}\text { Provide an environment that models and promotes } \\
\text { caring. }\end{array}$} & Faculty positive role modeling of caring \\
\hline & Workshops for clinical instructors on Caring Competency \\
\hline
\end{tabular}

\section{Conclusion}

Findings of this investigation further support Jean Watson's assumptions that caring is best demonstrated by using nursing actions based on theoretical knowledge that help the patient to become healthier while maintaining respect, dignity, 
self-worth and autonomy ${ }^{[1]}$. Results of this investigation suggest congruency with that of local and 'international studies that highlight instrumental nursing care as the most important behavior ${ }^{[6,9,11,13-15]}$.Therefore, this study strengthen the assumptions of previous study indicating satisfying human basic needs are as important in patients recovery. However, it is clear that student nurses should improve their communication and interpersonal skills necessary to establish a trusting relationship with their patient. The results generated from this investigation will help students and nurses better understand their patients’ world and improve their approach towards holistic nursing care.

Because caring has been equated to patient outcomes, students' caring competence upon graduation from nursing programs must be guaranteed. The suggested caring intervention guide may be useful for nurse educators in increasing knowledge and understanding of caring practices of student nurses, thus make them more caring practitioners in the future.

Since this study focuses on a small number of respondents, further study utilizing a bigger population maybe done. Furthermore, studies with focus on the spiritual aspect of care maybe conducted since spirituality can be an essential part of a patient's journey to health recovery and well-being.

\section{Acknowledgements}

The mentorship of Mrs. Madeliene H. Ampatin, nurse supervisor is acknowledged. Additionally, the researcher would like to thank all the patients who participated in this study.

\section{Conflict of interest}

I have no other financial, intellectual passion, political, religious, and institutional affiliations that might lead to a conflict of interest in making this paper.

\section{References}

[1] Watson, Jean. Assessing and Measuring Caring in Nursing and Health Sciences. 2002; 7-90. New York: Springer Publishing Co.

[2] Duffy, Joanne. Caring relationships and evidence-based practice: Can they coexist? International Journal of Human Caring. 2003; 7(3): 45-50.

[3] Wolf, Z.R., Colahan, M., Costello, A., Warwick, F., Ambrose, M.S., Giardino, E.R. Relationship between nurse caring and patient satisfaction. MEDSURG Nursing. 1998; 7(2): 99-105. PMid:9727124

[4] Issel, M., and Kahn, D. The economic value of caring. Health Care Management Review. 1998; 23(4): 43-53. PMid:9803318

[5] Latham, C. P. Predictors of patient outcomes following interactions with nurses. Western Journal of Nursing Research. 1996 ; 18 (5): 548-564. PMid:8918207 http://dx.doi.org/10.1177/019394599601800506

[6] Schultz, A. A., Bridgham, C., Smith, M. E., Higgins, D. Perceptions of caring: Comparison of antepartum and postpartum patients. Clinical Nursing Research. 1998; 7(4): 363-378. PMid:9919093 http://dx.doi.org/10.1177/105477389800700404

[7] Kimble, Lynn. Patients' Perception of Nurse Caring Behaviors in an Emergency Department. Marshall University Graduate School. (Unpublished Thesis). 2003.

[8] Woodward, W. Preparing a new workforce. Nursing Administration Quarterly. 2003; 27(3): 215-222. PMid:13677186

[9] Misao,H., Hayama,Y., Hishinuma,N. et al. A comparative research with regard to caring behaviors that patients/nurses recognized, Quality Nursing. 1997; 3(4): 63-71.

[10] Rosenthal, K. A. Coronary patients' and nurses’ perceptions of important nurse caring behaviors. Heart \& Lung. 1992; 21(6): 536-539. PMid:1447000

[11] Marini, B. Institutionalized older adults’ perceptions of nurse caring behaviors: A pilot study. Journal of Gerontological Nursing. 1999; 25(5): 10.

[12] Cronin, S. N., \& Harrison, B. Importance of nurse caring behaviors as perceived by patients with myocardial infarction. Heart \& Lung. 1988; 17: 374-380. PMid:3391789

[13] Huggins KN, Gandy WM, Kohut CD.Emergency DepartmentPatients’ Perception of Nurse Caring Behaviors.Heart and Lung. The Journal of Critical Care. 1993 Jul-Aug; 22(4): 365-64

[14] Mullins, I. L. Nursing caring behaviors for persons with acquired immunodeficiency syndrome/human immunodeficiency virus. Applied Nursing Research. 1996; 9 (1): 18-23. http://dx.doi.org/10.1016/S0897-1897(96)80335-1 
[15] Baldursdottir, M.S., and Jonsdottir, H. The importance of nurse caring behaviors as perceived by patients receiving care at an emergency department. Heart and Lung. 2002; 31 (1): 67-75. http://dx.doi.org/10.1067/mhl.2002.119835

[16] Gramling, L., and Nugent, K. Teaching caring within the context of health, Nurse Educators. 1998; 23 (2): 47-51. PMid:9582805 http://dx.doi.org/10.1097/00006223-199803000-00018

[17] Cronin, S. N., Harrison, B. Importance of nurse caring behaviors as perceived by patients with myocardial infarction. Heart \& Lung. 1988; 17: 374-380. PMid:3391789

[18] VahidZamanzadeh, RoghaiehAzimzadeh, Azad Rahmani and Leila Valizadeh. Oncology patients' and professional nurses' perceptions of important nurse caring behaviors [Internet]. Available from: http://www.biomedcentral.com/1472-6955/9/10

[19] Carlson, S., Kotze, WJ., Van Rooyen, D. Accompaniment needs of first year nursing students in the clinical learning environment. Curationis. 2003; 26(2):30-39. PMid:14596131 